\title{
Nurses' perception of the strategies to gaining professional power: A qualitative study
}

\author{
Rana Rezai Sepasi ${ }^{1}$, Fariba Borhani ${ }^{2}$, Abbas Abbaszadeh $^{3}$
}

\begin{abstract}
${ }^{1} \mathrm{PhD}$ Candidate for Nursing, Department of Medical Surgical Nursing, Razi School of Nursing and Midwifery, Kerman University of Medical Sciences, Kerman, Iran

${ }^{2} \mathrm{PhD}$ of Nursing, Associate Professor, Medical Ethics and Law Research Center, Shahid Beheshti University of Medical Sciences, Tehran, Iran

${ }^{3} \mathrm{PhD}$ of Nursing, Professor, Department of Medical Surgical Nursing, School of Nursing and Midwifery, Shahid Beheshti University of Medical Sciences, Tehran, Iran
\end{abstract}

\section{Type of article: Original}

\begin{abstract}
Background: Power in nursing is a broad concept that has a determining effect on the achievement of professional goals. Gaining power is essential for promoting the roles of nurses, improving their professional image and the consistent improvement of healthcare systems.

Objectives: This study was conducted to identify and clarify strategies for gaining power in the nursing profession through the experiences of Iranian nurses.

Methods: The present qualitative grounded theory study was conducted on fifteen participants selected through purposive sampling. Data were collected through individual, in-depth, semi-structured interviews. The data obtained were analyzed using the guidelines provided by Corbin and Strauss, (2008 edition). This study was carried out in Qazvin city of Iran and lasted fourteen months (2015-2016).

Results: The analysis of the data were classified under the main theme of gaining human-professional power based on individual and organizational capacities, divided into four main categories, including respecting human values and ethical principles (with two subcategories, keeping the human symbols of power and commitment to moral obligations of power), promoting professional interactions (with two subcategories, paying attention to intraprofessional communication and paying attention to interprofessional communication), attempting professional endurance (with two subcategories, raising self-confidence and having professional commitment), and valuing potential capacities (with two subcategories, regard for individual capacities and regard for organizational capacities).

Conclusion: The findings obtained suggest that success in gaining power in nursing, requires a cumulative focus on human, ethical, professional, individual and organizational capacities.

Keywords: Professional power, Nursing, Qualitative research, Strategy
\end{abstract}

\section{Introduction}

Power is a very abstract concept that is difficult to examine and define (1). However, power can be defined as something that can enable individuals or groups to achieve their goals. So, power provides individuals or groups the potential for changing attitudes and the behavior of others (2). When power is defined as the capacity to achieve goals, it becomes a significant source in nursing, which necessitates further study (1). Today, a nurse should be a strategic planner, a human resources expert, a risk manager and a high-quality specialist who is able to understand the complexities of clinical practice (3). On the other hand, jobs which have been recognized as professions (i.e. nursing), should be independent and self-directed and have control over the content of their work (4). But nurses have often described themselves as being far away from the hierarchical decision-making process in healthcare

\section{Corresponding author:}

Professor Dr. Abbas Abbaszadeh, Department of Medical Surgical Nursing, School of Nursing and Midwifery, Shahid Beheshti University of Medical Sciences, Tehran, Iran.

Tel: +98.2188655366, Fax: +98.2188202521, Email: aabaszadeh@sbmu.ac.ir

Received: March 29, 2017, Accepted: May 28, 2017, Published: July 2017

iThenticate screening: April 27, 2017, English editing: June 12, 2017, Quality control: July 02, 2017

(C) 2017 The Authors. This is an open access article under the terms of the Creative Commons Attribution-NonCommercialNoDerivs License, which permits use and distribution in any medium, provided the original work is properly cited, the use is non-commercial and no modifications or adaptations are made. 
systems and to be obliged to comply with the decisions others have taken because did not have enough power $(5,6)$. Nurses need power that helps them to seize opportunities for the creative application of their knowledge and skills (7). A powerful nurse can also increase her patients' power and give them a sense of empowerment and positively affect their outcomes (8). As Sepasi stated in her 2016 study, "power is a tool for professional excellence" (9). While nurses endure a disproportionate amount of responsibility, and should be accountable for many of the events that occur in the clinical setting, they have limited control over the decisions that affect patient care (10). An extensive study in different countries has shown that feeling of powerlessness among nurses and lack of control over their work affect the quality of patient care and lead to job dissatisfaction and turnover. This is a wakeup call for quality of care and patient safety (11). Nurses are expected to provide high quality care for their patients and empower them to independence, but providing such care depends on the amount of their professional power (12). Powerful nurses have more successful professional performance and will progress in their work. They are more satisfied and feel to be more efficient and provide a higher quality of care (8). It is evident that the nursing profession and nurses need to understand, promote and use power in order to be able to provide high-quality and safe patient care, initiate and accept changes and help develop health policies that support the patients and nurses (13). How can power be achieved? There is no consensus on the source of gaining power in the nursing profession. The fact remains that how nursing power is obtained and how it becomes evident is an abstract concept for many nurses (9). Some believe that nursing power derives not only from the nurses' clinical practice, but also from their contributions to the larger social and political arena, and thus regard education and practice as major political institutions (7). Bressan noticed in her 2016 study, the medical dominance of the obstacles to the professional development of modern nursing. She has mentioned access to an exclusive body of knowledge and recognition of specific professional nursing skills and knowledge as nursing growth factors (14). The review of the existing literature indicates that there are few studies which are based on strategies leading to gaining professional power, using nurses' knowledge, experiences and attitudes. Most of the present studies are based on organizational theories and have been done quantitatively, while qualitative studies, may help us to examine this important issue deeply. Based on its nature, complexity and being in the context of social processes, this study needed to be carried out in its original context and not in isolation from that. This investigation should be carried out thoroughly and comprehensively with a holistic view. These features could be found only in a qualitative approach, in a way to understand the various aspects of the phenomenon under study from the perspective of the participants to achieve an overall perception of the concept. Given the significant effect of power and its absence on nurses' performance in their extensive roles when faced with increased changes in the health system and given the numerous ambiguities about gaining power in nursing at both global and national levels, the present study was conducted to identify and clarify strategies for gaining power in the nursing profession using the experiences of Iranian nurses and with a qualitative approach.

\section{Material and Methods}

This study was carried out qualitatively using grounded theory approach. The qualitative approach examines human phenomena in the context of social sciences. This method of research can be effective in clarifying ambiguous and unknown areas, and provides the best way of describing fundamental social processes in life (15). The participants were selected among nurses who were active in clinical, managerial and educational activities, had at least five years of work experience and had distinct experiences or views on the research subject. Sampling was purposive in the beginning and theoretical in later stages. A total of 15 participants holding different positions were selected for the study, including head nurses, matrons, clinical supervisors, faculty members and members of the board of directors of the Iranian Nursing Organization (INO). They ranged from 36 to 49 in age and had a work experience of 10 to 25 years. In terms of gender, nine participants were female and six were male. None of the participants withdrew from the study. The study lasted 14 months (from June 2015 to August 2016). The research setting consisted of participants' workplaces, including the hospitals, nursing and midwifery school and the Qazvin office of the INO. Qazvin is one of Iran's major cities. In view of the general research question of "How is the process of gaining power in the nursing profession?" Data were collected through in-depth, semi-structured interviews and open-ended questions. The interviews were held in private locations and lasted from 60 to 90 minutes and began with more general questions and were gradually directed toward the research objectives. All the interviews were audio recorded. The questions posed included "What is your definition of being powerful? What strategies do you use for gaining power? Please tell us about your experiences of feeling powerful or powerless in fulfilling your professional duties." Each interview became a transcript as soon as possible and directed the researchers in the later interviews. In order to do data analyzing, the researchers used the encoding method, which means that each of transcripts was broken to several meaning units as codes. The coding process of each text was performed using the in vivo and inferential approach. For example, some first level codes were obtained from the following quote: (..."The nurse is 
not allowed to do much of what she thinks is right based on her nursing diagnosis that nursing discipline has allowed her to do, some surgeons do not allow you to perform even a simple procedure on their patients. In this case you feel that nursing is powerless"...) (participant No: 02). So, some codes were extracted as follows: "Allowed independent actions in nursing", "Belief in the ability to do the right thing", "Restrictions", "Lack of independence in the performance", "Feeling that nursing is powerless". All the codes extracted from each text were stored in separate tables. By performing the constant comparison, the codes were all classified and integrated and thus, the primary classes were extracted and, with the integration of primary classes, main classes were emerged (selective coding) (16). In parallel with the analysis of data, some evaluative criteria were used to ensure accuracy and trustworthiness of the data. After extracting the initial codes of each interview and at every step of the analysis, interviews, codes and emerged categories were presented to the consultants and supervisors; the accuracy was assessed and verified by them. After a final agreement at any stage, the process was continued. Prolonged engagement in the field and member check helped researchers to be ensured of the findings' credibility. Other measures included allocating enough time to data collection, using experts for the analysis of the data and ensuring agreement with the participants about the generated categories. To enhance the usability in terms of results in other groups or conditions, the research team considered that some measures included trying to do further interviews with the participant from a wider variety of workplaces, surveying some other nurses' views who didn't participate in the study about the results and findings. So, the possibility of transferring the findings on the other situations and conditions may become greater. Maximum variation sampling was also used to select participants from different settings and with different positions and varying work experiences (17). Regarding ethical considerations, this study was conducted with the ethical approval of the Research Center of Kerman University of Medical Sciences in Iran; code K/93/250. All the participants received adequate information about the objectives and methods of the study, the voluntary nature of participation and their right to withdraw from the study, and submitted an informed consent form. The researchers maintained the confidentiality of participants' details and identity and the data obtained through their interviews.

\section{Results}

The analysis of the data obtained on strategies for gaining power in nursing were classified under the main theme of "Gaining human-professional power based on individual and organizational capacities", divided into four main categories, including respecting human values and ethical principles, promoting professional interactions, keeping professional endurance and valuing potential capacities (Table 1). The categories are described in the following.

Table 1. The Classification of Strategies for Gaining Power in the Nursing Profession

\begin{tabular}{|l|l|}
\hline Gaining Human-Professional Power Based on Individual and Organizational Capacities \\
\hline Respecting Human Values and Ethical Principles & Keeping the Human Symbols of Power \\
\cline { 2 - 2 } & Commitment to Moral Obligations of Power \\
\hline \multirow{2}{*}{ Promoting Professional interactions } & Paying Attention to Intraprofessional Communication \\
\cline { 2 - 2 } & Paying Attention to Interprofessional Communication \\
\hline \multirow{2}{*}{ Attempting Professional Endurance } & Raising Self-confidence \\
\cline { 2 - 2 } & Having Professional Commitment \\
\hline \multirow{2}{*}{ Valuing Potential Capacities } & Regard for Individual Capacities \\
\cline { 2 - 2 } & Regard for Organizational Capacities \\
\hline
\end{tabular}

\subsection{Respecting human values and ethical principles}

Based on the findings, respecting human values and ethics in the line of duty and professional communication, plays a very important role in achieving nurses' personal and professional power. Participants considered some of the values and principles of humanity and morality that during their own careers, have had positive feedback to increase their power in the eyes of patients, colleagues and doctors effectively. This class has two subclasses including human symbols of power and moral obligations of power, which are described.

3.1.1. Keeping the human symbols of power

The findings of this study show that one of the foundations of gaining power in the nursing profession is relying on human values. These values are raised in the profession and in relation to others, including the patients, the patient caregivers, the colleagues and the subordinates. Goodwill, empathy with the patient, empathy with colleagues, selfmastery, patience, tolerance and being understanding are examples of human behaviors that can lead an individual to be accepted, and will increase their influence on others. One of the participants who was a supervisor stated: ("In terms of my managerial power, I'm more successful than my colleague who does not understand others and shows 
no good will" ...) (Participant No: 01). In explaining the reason for her success in managing the ward, one of the head nurses said: (..."I don't remember ever having yelled at anyone in the ward, but I have behaved so that everyone has performed their duties properly and sometimes when I've checked their work, I've asked them to do the job one more time, without any insults, and maybe then asked for the job a third time, or even a fourth time, but all of this with no insults"...) (Participant No: 03)

3.1.2. Commitment to moral obligations of power

The findings suggest that, although concepts such as responsibility, accountability, respect for justice, being trustworthy, reliable and confidential are among the concepts in professional ethics in nursing and are a subset of biomedical ethics; commitment to respecting these ethics contributes to the gaining of power in nurses. For example, the availability of the nurse to meet the patient's needs will attract the patient's trust and create confidence in the nurse and enhance her/his professional status. One of the participants discussed the patients' trust in the nurses and said (..."The patient fully realizes the availability of a nurse. If I am available to meet his needs while caring him, he will accept me easier, will pay attention to me and will trust me. The patient's trust in the nurse essentially elevates her status and also her power"...) (participant No: 08)

\subsection{Promoting professional interactions}

The findings suggest that professional interactions are important issues in gaining power in nursing. Neglecting these, obstructs the goal of gaining power. Many of the participants pointed to the importance of professional solidarity in achieving professional power. They believed the ethics of avoiding individualism, distrust to each other and conflicts are prerequisite to achieve a strong professional position and power. This view is related to all professional communications, both inter and intra healthcare disciplines and also nursing. Based on the terms of participants, these interactions are classified under the two subcategories of intraprofessional communication and interprofessional communication.

\subsubsection{Paying attention to intraprofessional communication}

According to many participants; some of the positive aspects of intraprofessional communication play a significant role in strengthening professional solidarity, unity, empathy and the sense of power. Some of these objects include consideration for the importance of trusting in colleagues, respecting them, providing professional support to them and supporting meritocracy in assuming organizational positions. One of the participants discussed this importance and said: (... "As nurses, we should show more empathy toward one another, support each other and not feel joy at each other's failure. We should support each other from the top to the bottom, just as is the case in other professions. We will be more powerful if we learn to support one another" ...) (Participant No: 10). According to the participants, one of the important elements of professional solidarity was to be a member of nursing professional organizations which advocate nurses' rights. But unfortunately, the number of such nursing organizations' members is much less than the total nurses. One of the participants who was a member of the Board of Directors of the INO discussed this issue and said: (... "The larger the number of our union members, the greater is its power and authority, and the more it can offer. But the greatest weakness of our nursing organization is that joining it is not mandatory. I won't listen to what the organization asks of me unless I'm a member" ...) (Participant No: 14)

\subsubsection{Paying attention to interprofessional communication}

The participants believed that promoting interprofessional communication requires a focus on academic and practical capabilities in nursing care and on involving the nurses in treatment and care planning. This focus will strengthen nurses' status and increase their authority to deliver high-quality care. The first step is to believe in teamwork and the participation of all the members of the care team in providing care to the patients. It is important to institutionalize this belief in all healthcare groups. One of the participants who was formerly an operating room technician said, (... "The healthcare workers don't know about teamwork. For example, an operating room technician, who herself is a member of the nursing staff and is part of the field of nursing, does not properly recognize the nurses' status and considers her job one rank above the nurses"” ...) (Participant No: 04). Participants pointed to some measures that were able to change the present status of interprofessional interactions in healthcare environments from domination, obedience and coercion to cooperation, exchange of ideas and participation. Some of these measures are learning to properly notify others of their errors, using respectful words when dealing with both superiors and subordinates, talking with utmost respect, avoiding insults and respecting others' presence (including the patients' and their families') in one's communication. The same participant gave an example and said: (..."At times, when I was working in the operating room, I hinted some things that I had learned from one surgeon to another surgeon gently and politely. He embraced it. But too often, the same surgeon did not hear the remarks of my other colleagues and had a bad deal. I thought to myself that the wording makes him give importance to me but not to others."...) (Participant No: 04) 


\subsection{Attempting Professional Endurance}

This theme was derived from two subcategories, including raising self-confidence and having professional commitment. Participants in this study described their work environment as very complex and involved, with many contradictions and disruptions. In their view, difficult working conditions, pressures and conflicts in the workplace have led nurses to loss of the incentive to work and leave work. They also knew some existing conditions in conflict with the interests of the patient, and believed that to protect the rights of patients and their own rights, nurses must resist the pressures. From the perspective of the participants, nurses have the right to use their knowledge, skills and experiences to protect patients and reduce possible medical errors at any time. They can present their power by correct application of knowledge and skills at appropriate times and also by being committed to the nursing profession and patients' rights.

\subsubsection{Raising Self-confidence}

Based on the experiences of participants, despite having the related knowledge, the existence of patriarchy in the healthcare workplaces does not allow nurses to comment on patient treatment or indeed patient care. This suppression prevents the emergence of confidence in nurses and creates the state of passivity. But many participants believed that nurses need to increase their self-confidence and use their knowledge and skills in the interest of the patients. For example, they noticed that nurse's ability to recognize the patient's clinical status and notify and alert the doctor, without fear of his negative impact, will enhance the self-esteem of the nursing staff. According to the close attention and wider relevance between the nurse and the patient, the nurse is more attuned to signs and symptom variations, so their correct diagnosis will affect the physician's treatment decisions. As this happens, the trust to knowledgeable nurses will be increased and so will nurses professional power. One of the participants discussed this subject and said: (... "It has happened to me so many times that, despite being sure about something, I haven't been able to bring myself to tell it to the physician or the patient. I haven't had the power because I didn't believe in myself or in my knowledge" ...) (Participant No: 02)

\subsubsection{Having professional commitment}

In this study, the concept of professional commitment is a conceptual umbrella that covers several other concepts, such as work motivation, professional dependence and professional belonging. According to the participants, the potential to achieve professional power can be detected in the nurse's interest in the field of nursing, her motivation for work and professional advancement, and efforts to promote the profession and earn points for it. The participants noticed that an individual who is dependent on her profession shows endurance in the face of its challenges and does not hesitate to do everything in his or her power to resolve the problems. One of the participants said: (..."First, you should be able to come along with your job and accept yourself as a nurse. When you're wearing the white coat, you are a nurse. Then other issues can be marginal. You can be strong and fight."...) (participant No: 08). Reinforcing the insight and attitude of commitment to the nursing profession has a positive impact on improving caring performance and professional development as well. As in this perspective, professional development is synonymous with professional power. One of the participants who was seeking the start of change in nursing and gaining power within himself said: (... "When I'm not proud of my career and have doubts about it and look at it only as a means of earning a living, well, nothing will improve then. The mindset ought to be positive; change begins with me" ...) (participant No: 14)

\subsection{Valuing potential capacities}

According to the findings, another factor at play is to value potential capacities. This theme is derived from a positive vision of participants to the abilities of nurses and also the workplace as a single organization. They emphasized the abilities of nurses to be seen and these capabilities to be used in the nursing practice scope. According to the participants, attention to these potentials not only will improve the quality of care, but lead to selfgrowth and strengthen self-confidence in the nurses and motivate them for professional growth, and furthermore, can increase nurses' power. This category consists of two subcategories, namely regard for individual capacities and regard for organizational capacities.

\subsubsection{Regard for individual capacities}

At the individual level, some capacities were noticed by participants which identification, development and valuation of them would contribute to gaining nursing professional power. Among these features were having knowledge, experience, determination, leadership skills, courage, perseverance and creativity. It is fair to claim that a nurse's specialized knowledge and her ability to use this knowledge make up the main feature involved in promoting her individual and professional status, as emphasized by all the participants. Expressing her experiences of the positive effect of the nurse's knowledge and experience on her relationship with the physician, one participant said: (..."Nurses must improve their scientific and practical information. As much scientific and practical abilities we have, as powerful we are"...) (participant No: 01). Also; having courage and determination allows the individual 
to not to be afraid of challenges and thus enables the nurse to affect the progress of her work. One participant said about these features: (... "Very often, we are seeking this status, but our superiors either lack this courage themselves or have deprived us of it. They limit us. I can learn more from a manager who has greater confidence and courage" ...) (participant No: 06)

3.4.2. Regard for organizational capacities

According to findings, another important part of strategies is to train and strengthen the organizational attitude and insight of employees and managers. Some of the participants talked about the role of their organizations in providing conditions necessary to develop workplaces, which lead to have more powerful nurses. In their view nurses do not possess opportunities to progress and growth in their workplaces. According to participants, their organizations are reluctant to make them powerful and there is essentially no organizational vision and teamwork attitude in healthcare environments. While the successful creation of the organizational attitude increases work motivation and organizational commitment among the nursing personnel on the one hand, it decreases the strong opposition to the empowerment of a major part of the healthcare system (i.e. nurses) on the other. From the participants' view; planning and facilitating the growth and development of individual capabilities and assuming positions and power in accordance with these capabilities by the organization, have common individual and organizational interests for health systems. One participant noted the significant role of the organizations and said: (... "How much room does the system allow for these competent people to grow? The organization needs to have plans for this positive power. If both are following the same direction, I mean, if the organization creates conditions that are conducive to growth, and at the same time, I have the means as someone who seeks positive power, I will ultimately find a status of power." ...) (participant No: 07).

\section{Discussion}

The findings suggest that success in gaining human-professional power in the nursing profession requires a focus on human, ethical, professional, individual and organizational capacities. This study shows that people will not become powerful only by being assigned power and taking advantage of opportunities and resources; rather, they should also boast certain individual, human and moral features to maintain and use this power. A 2012 study by Rao suggests that structural empowerment strategies based on Kanter's theory and implemented with an emphasis on organizational improvement are not sufficient, and nursing should seek to uncover the complex interactions that shape nursing empowerment (18); these findings are consistent with the findings of the present study. Although the emphasis on human values and ethical and professional principles in the nursing practice can be extracted from various texts $(19,20)$, their effect on a nurse's power was more distinctly perceived in the present study. In a sense, a nurse's power signifies her acceptance by others (patients, colleagues and other healthcare personnel) as a nurse who follows human, ethical and professional principles in her professional interactions and who establishes a relationship of trust and encourages patients to have more trust in the healthcare personnel, thereby leading to the enhancement of her professional power. In Iranian-Islamic culture, people's regard for human and ethical principles is what makes them valuable, worthy of respect and influential, and helps improve their status and social power (21). These findings corroborate the findings of the present study regarding the effect of respect for human values and ethical principles on individual and professional power in nurses. The findings of this study showed that professional communication plays a key role in the development of power in nursing. Noting the loss of respect and civility in healthcare workplaces, Cowin emphasizes the importance of an open communication of utmost respect in complex and dynamic academic health settings in his 2013 study (22). A 2012 study by Laschinger also showed that intervention programs seeking to improve civility and respect in workplace interactions are effective in the empowerment of nurses (23). It seems, modifying and improving professional interactions leads to the progress and empowerment of healthcare professionals. The present study divides the concept of professional endurance into two parts, including raising self-confidence and having professional commitment. One method of empowering human capital in each organization is to increase the members' self-confidence (24). Nurses need to strengthen their selfconfidence in terms of knowledge, skills and diagnosis and decision-making abilities in order to be able to use their attributes for promoting the quality of patient care, on the one hand, and to present themselves and the nursing profession at the organizational and community levels, on the other. It should be noted that knowledge is a precursor to self-confidence, although not a sufficient condition. Some other antecedents, such as support, experience and success, are also necessary (25). According to the participants, professional commitment is used in the sense of belonging to a profession and making efforts to promote it and remove the barriers to its development. In other texts, professional commitment is also defined as "(a) the belief in professional goals and values; (b) willingness to make significant efforts on behalf of the profession; and (c) the desire to remain part of the profession" (26). Professional commitment is linked to but distinct from organizational commitment, and develops beyond the organization's boundaries (27). Although professional commitment has a positive relationship with job satisfaction, patient safety, 
high-quality care and a lower intention to quit (28), in the present study, it appears to have a direct and positive relationship with gaining professional power in nurses. A nurse's knowledge and skills make up the principal base of her individual power, as discussed in many other studies (29-31). Strengthening the nurses' knowledge base is a responsibility of both the nurses and the organizations. Providing in-service training and giving periodical theoretical and practical tests can be helpful. Some studies also argued that facilitating the means of continuous education is crucial to gaining power in nursing (32). The present study revealed that having regard for other individual attributes and their positive contributions provide the mental and practical power required for their powerful performance. This finding is not consistent with the findings of studies based on Kanter's theory, in which gaining power is deemed possible by mere organizational resources (23), as it considers individual features important as well. The disparity of findings may be due to differences in the study methods, as the present study is qualitative while others have been quantitative. In qualitative research, findings are based on people's experiences, attitudes and interactions and they therefore appear to have a greater depth than the findings obtained through quantitative research. From an organizational perspective, nurses have a special capacity as the largest group providing healthcare. The intraprofessional support of the nursing personnel by nursing managers at the organizational level and strengthening nursing organizations and associations at the national level can help enhance professional integrity; this integrity then increases the likelihood of gaining professional power through efforts such as participation in professional planning, policy-making and legislation for promoting the nursing profession. Other studies have also obtained similar results (33). Some also proposed professional support as effective in the creation of professional solidarity and the empowerment of nurses (34). Based on findings, one of the main challenges of the Iranian Nursing Organization is the lack of active members, even though interaction and communication between members of a profession contribute significantly to the development of that profession (35). Some also believe that membership in nursing associations is not optional in the modern age; rather, it is a duty and responsibility for all members of the profession so as to affect the outcomes of healthcare systems (36). Encouraging nurses for membership and active participation in professional organizations is therefore necessary for nurses to gain professional power.

\section{Study Limitations}

The findings of this study were obtained from participants' data in the city of Qazvin, Iran -. Since the atmosphere governing healthcare systems can be different in different cities, the findings may be somewhat affected by this difference.

\section{Conclusions}

Although gaining professional power in nursing appears difficult, it is not impossible. Although in the past, the submissiveness of nursing as a distinct profession and its humanitarian and philanthropic nature and the diversity and complexity of professional relations were impediments to power-seeking ideas in nursing, today, the same factors provide ample reason to seek to change the attitudes in healthcare systems and to respect the power inherent in nurses' knowledge, skills and experience for influencing these systems. The key factor in the success of a strategy is to create a positive attitude toward it. Getting nurses to have a higher regard for human, ethical and professional values, creating self-confidence in them and enhancing their capacities are the precursors to a positive change that would be impossible without first correcting defective professional interactions in health systems. Institutionalizing active participation in professional nursing organizations helps support nurses and facilitates their favorable performance in the political, economic, cultural and legal atmosphere governing the healthcare systems in addition to helping strengthen these organizations, which is itself, synonymous with the empowerment of the nursing profession.

\section{Acknowledgments:}

This paper is the result of a $\mathrm{PhD}$ thesis, entitled "Explaining the concept of power and the process of gaining power in the nursing profession". Hereby, the authors would like to express their gratitude to all the participants for their cooperation and assistance in the study, and for sharing their experiences and views.

\section{Conflict of Interest:}

There is no conflict of interest to be declared.

Authors' contributions:

All authors contributed to this project and article equally. All authors read and approved the final manuscript. 


\section{References:}

1) Katriina P, Sari V, Anja R, Christina S, Paula A, Tarja S. Nursing power as viewed by nursing professionals. Scand J Caring Sci. 2013; 27(3): 580-8. doi: 10.1111/j.1471-6712.2012.01069.x. PMID: 23003338.

2) Huston CJ. Professional issues in nursing: Challenges and opportunities. Third ed: Lippincott Williams \& Wilkins; 2014.

3) Trus M, Razbadauskas A, Doran D, Suominen T. Work-related empowerment of nurse managers: A systematic review. Nurs Health Sci. 2012; 14(3): 412-20. doi: 10.1111/j.1442-2018.2012.00694.x. PMID: 22676260 .

4) Pescosolido BA. Professions and the Public. The Wiley Blackwell Encyclopedia of Health, Illness, Behavior, and Society: John Wiley \& Sons, Ltd; 2014.

5) Traynor M, Boland M, Buus N. Professional autonomy in 21st century healthcare: Nurses' accounts of clinical decision-making. Soc Sci Med. 2010; 71(8): 1506-12. doi: 10.1016/j.socscimed.2010.07.029. PMID: 20797814.

6) Hassankhani H, Abri S, Zamanzadeh V, Aghdam ARM. Iranian Nurses Perception of Control over Nursing Practice. European Journal of Scientific Research. 2012; 75(1): 5-13.

7) D'Antonio P, Connolly C, Wall BM, Whelan JC, Fairman J. Histories of nursing: The power and the possibilities. Nurs Outlook. 2010; 58(4): 207-13. doi: 10.1016/j.outlook.2010.04.005. PMID: 20637934, PMCID: PMC2907354.

8) Spence Laschinger HK, Gilbert S, Smith LM, Leslie K. Towards a comprehensive theory of nurse/patient empowerment: applying Kanter's empowerment theory to patient care. J Nurs Manag. 2010; 18(1): 4-13. doi: 10.1111/j.1365-2834.2009.01046.x. PMID: 20465724.

9) Sepasi RR, Abbaszadeh A, Borhani F, Rafiei H. Nurses' Perceptions of the Concept of Power in Nursing: A Qualitative Research. J Clin Diagn Res. 2016; 10(12): LC10-LC15. doi: 10.7860/jcdr/2016/22526.8971. PMID: 28208886, PMCID: PMC5296459.

10) Perron A. Nursing as 'disobedient' practice: care of the nurse's self, parrhesia, and the dismantling of a baseless paradox. Nurs Philos. 2013; 14(3): 154-67. doi: 10.1111/nup.12015. PMID: 23745657.

11) Aiken LH, Sloane DM, Bruyneel L, Van den Heede K, Sermeus W. Nurses' reports of working conditions and hospital quality of care in 12 countries in Europe. Int J Nurs Stud. 2013; 50(2): 143-53. doi: 10.1016/j.jinurstu.2012.11.009. PMID: 23254247.

12) Trus $M$, Suominen $T$, Doran $D$, Razbadauskas A. Nurses' perceived work-related empowerment in Lithuanian context. Scand J Caring Sci. 2011; 25(3): 599-607. doi: 10.1111/j.1471-6712.2011.00871.x. PMID: 21362005.

13) Farsi Z, Dehghan-Nayeri N, Negarandeh R, Broomand S. Nursing profession in Iran: an overview of opportunities and challenges. Jpn J Nurs Sci. 2010; 7(1): 9-18. doi: 10.1111/j.1742-7924.2010.00137.x. PMID: 20618672.

14) Bressan V, Tolotti A, Barisone M, Bagnasco A, Sasso L, Aleo G, et al. Perceived barriers to the professional development of modern nursing in Italy - A discussion paper. Nurse Educ Pract. 2016; 17: 527. doi: 10.1016/j.nepr.2016.02.007. PMID: 27038088.

15) Burns N, Grove S. Understanding Nursing Research: Building an Enidence- Based Practice. 4 ed: Saunders pub; 2009.

16) Corbin J, Straus A. Basics of qualitative research, techniques and procedures for developing Grounded Theory. 3th ed. California: SAGE publications; 2008. doi: 10.4135/9781452230153.

17) Speziale HS, Streubert HJ, Carpenter DR. Qualitative research in nursing: Advancing the humanistic imperative. Lippincott Williams \& Wilkins; 2011.

18) Rao A. The Contemporary Construction of Nurse Empowerment. J Nurs Scholarsh. 2012; 44(4): 396-402. doi: 10.1111/j.1547-5069.2012.01473.x. PMID: 23062275.

19) Aitamaa E, Leino-Kilpi H, Puukka P, Suhonen R. Ethical problems in nursing management: the role of codes of ethics. Nurs Ethics. 2010; 17(4): 469-82. doi: 10.1177/0969733010364896. PMID: 20610580.

20) Ravani pour M, vanaki Z, afsar L, Azemian A. The standards of professionalism in nursing: the nursing instructors' experiences. Evidence Based Care. 2014; 4(1): 27-40. doi: 10.22038/EBCJ.2014.2392.

21) Borhani F, Hosseini S, Abbaszadeh A. Commitment to care: a qualitative study of intensive care nurses' perspectives of end - of - life care in an Islamic context. Int Nurs Rev. 2014; 61(1): 140-7. doi: 10.1111/inr.12079. PMID: 24382147.

22) Cowin LS, Eagar SC. Collegial relationship breakdown: A qualitative exploration of nurses in acute care settings. Collegian. 2013; 20(2): 115-21. doi: 10.1016/j.colegn.2012.04.008. PMID: 23898600. 
23) Spence Laschinger HK, Leiter MP, Day A, Gilin-Oore D, Mackinnon SP. Building empowering work environments that foster civility and organizational trust: Testing an intervention. Nurs Res. 2012; 61(5): 316-25. doi: 10.1097/NNR.0b013e318265a58d. PMID: 22935768.

24) Farzianpour F, Fouroshani AR, Beyzaiee S, Hosseini S. Evaluation of the Self-Esteem Managers in Clinical Wards of Hospitals Affiliated to Tehran University of Medical Sciences. World Applied Sciences Journal. 2012; 16(5): 686-92.

25) White KA. Self - Confidence: A Concept Analysis. Nursing Forum. 2009; 44(2): 103-114. doi: 10.1111/j.1744-6198.2009.00133.x.

26) Teng CI, Dai YT, Shyu YI, Wong MK, Chu TL, Tsai YH. Professional Commitment, Patient Safety, and Patient - Perceived Care Quality. J Nurs Scholarsh. 2009; 41(3): 301-9. doi: 10.1111/j.15475069.2009.01289.x. PMID: 19723279.

27) McCabe TJ, Sambrook S. Psychological contracts and commitment amongst nurses and nurse managers: A discourse analysis. Int J Nurs Stud. 2013; 50(7): 954-67. doi: 10.1016/j.ijnurstu.2012.11.012. PMID: 23228863.

28) Borhani F, Jalali T, Abbaszadeh A, Haghdoost A. Nurses' perception of ethical climate and organizational commitment. Nurs Ethics. 2014; 21(3): 278-88. doi: 10.1177/0969733013493215. PMID: 24019306.

29) Manojlovich M. Power and Empowerment in Nursing: Looking Backward to Inform the Future. Online J Issues Nurs. 2007; 12(1): 2. PMID: 17330984.

30) Oudshoorn A. Power and empowerment: critical concepts in the nurse-client relationship. Contemp Nurse. 2005; 20(1): 57-66. doi: 10.5172/conu.20.1.57. PMID: 16295342.

31) Adib Hajbaghery M, Salsali M. A model for empowerment of nursing in Iran. BMC Health Serv Res. 2005; 5(1): 24. doi: 10.1186/1472-6963-5-24. PMID: 15769297, PMCID: PMC1079834.

32) Eskandari M, Abbaszadeh A, Borhani F. Barriers of referral system to health care provision in rural societies in Iran. J Caring Sci. 2013; 2(3): 229-36. doi: 10.5681/jcs.2013.028. PMID: 25276731, PMCID: PMC4134155.

33) Casey M, Saunders J, O'Hara T. Impact of critical social empowerment on psychological empowerment and job satisfaction in nursing and midwifery settings. J Nurs Manag. 2010; 18(1): 24-34. doi: 10.1111/j.1365-2834.2009.01040.x. PMID: 20465726.

34) Adib-Hajbaghery M, Yamini EA. Nurses perception of professional support. Feyz Journals of Kashan University of Medical Sciences. 2010; 14(2).

35) Esmaeili M, Dehghan-Nayeri N, Negarandeh R. A review of the opportunities and challenges facing the nursing associations in Iran. Int Nurs Rev. 2012; 59(2): 168-74. doi: 10.1111/j.1466-7657.2012.00981.x. PMID: 22591086.

36) Farokhzadian J, Nayeri ND, Borhani F. Rocky milieu: Challenges of effective integration of clinical risk management into hospitals in Iran. Int J Qual Stud Health Well-being. 2015; 10: 27040. doi: 10.3402/qhw.v10.27040. PMID: 25968444, PMCID: PMC4429258. 